\title{
An Investigation into the Combustion of Mixed Fuel Consisting of Bituminous Coal and Crude Bio-oil
}

\author{
Hazlin Hamdan ${ }^{a}$, Munawar Zaman Shahruddin ${ }^{b}$, \\ Ahmad Rafizan Mohamad Daud ${ }^{\mathrm{c}}$, Syed Shatir A. Syed-Hassan ${ }^{\mathrm{d}^{*}}$
}

\author{
Faculty of Chemical Engineering, Universiti Teknologi MARA, 40450 Shah Alam, Selangor, \\ Malaysia \\ ahazlin.hamdan@yahoo.com, bmunawar_zaman@salam.uitm.edu.my, \\ ahmad2057@salam.uitm.edu.my, ${ }^{\mathrm{d}^{*}}$ shatir@salam.uitm.edu.my
}

Keywords: Slurry Fuel, Bituminous Coal, Crude Bio-oil, Biomass, Kinetic Analysis, Combustion

\begin{abstract}
The combustion of bituminous coal, bio-oil, and their slurry mixtures were performed under air atmosphere using Thermogravimetric Analyzer (TGA). All samples were run from room temperature to $110^{\circ} \mathrm{C}$ and held for 10 minutes before the temperature was ramped at the heating rate of $10^{\circ} \mathrm{C} / \mathrm{min}$ to $1100^{\circ} \mathrm{C}$.Kinetic evaluation was conducted using a simple Arrhenius-type kinetic model with first-order decomposition reaction. Apparent activation energy, Ea, and pre-exponential factor, A, were calculated from the modelling equation. Results reveal that the reactivity of CBS fuel is higher than a single coal fuel to which the addition of bio-oil helps to increase the combustion performance of the blends. The optimum fuel ratio appears at 50:50 ratio with equal contribution of coal and bio-oil properties that contribute to the increase in volatile matter causing maximum combustion rate achievable at much lower temperature compared to single coal fuel.
\end{abstract}

\section{Introduction}

World necessity lies on water and energy supplies. With continuous surge on populations and economies, the global energy demand is foreseen to climb up by more than a third by 2035, in which, $60 \%$ of the increment is demanded by China, India and Middle Eastern countries. Fossil fuel by far, has been the ultimate source of world energy production and coal is one of them. However, coal-burning activity in power generation industry has become the major source of carbon emissions that contributed to the horrific climate change. Alternatively, world is fixed upon a rapid transition into the utilization of renewable energy sources such as the engaging biomass.

Abundance of biomass; a carbon-neutral resource will initiate a carbon-free emission. However, a complete replacement of coal with biomass in short-term period is unachievable due to the economic and technical constraints. Co-combustion of coal-biomass in the existing coal-fired power plants has been proposed to quell coal consumption. This mixed generation has become one of the fastest and low-cost alternative solution in recent years with proven study in reducing $\mathrm{NO}_{\mathrm{x}}$ and fossil $\mathrm{CO}_{2}$ emissions [1]. Unfortunately, the unattractive characteristics of the biomass such as bulky, fibrous, high moisture content and low energy density lead to logistic and cost problems and may result in a bigger carbon footprint [2]. With that, biomass conversion into bio-oil is being proposed to develop an energy mix technology known as Coal-biooil slurry (CBS) fuel.

Bio-oil, a high-density oxygenated liquid that can be extracted from fast-low-cost pyrolysis [3] of biomass, is useful in overcoming ash-related problems resulting from combustion of raw biomass. With pyrolysis as a pre-treatment process, ash production can be minimized from being a new industrial waste. Bio-oil is higher in energy density than biomass thus making its transportation to the plant site and direct utilization become economically feasible [4]. To investigate the combustion characteristics of CBS fuel, thermogravimetric technology is used as it is widely applied by many former researchers in designing combustion and pyrolysis equipment [5]. Even though research on combustion characteristics of CBS fuel via TGA has never been reported, all thermal-kinetic-related-studies of coal, biomass, and bio-oil together with coal-biomass blends can be regarded as close references. Additionally, a study on thermal behavior of CBS fuel from the same bituminous coal and oil palm empty fruit bunch bio-oil [6] has been previously reported by 
our group but under inert atmosphere. Still, the study can be linked together for relevancy evaluation.

Although the study on combustion behaviour of coal is widely available, the bio-oil fuel combustion behaviour is still very limited. Only a few studies on the devolatilization and kinetics of single bio-oil ever reported by several researchers on beech wood bio-oil, palm empty fruit bunch bio-oil and pinewood bio-oil [6,7]. As literatures claimed that biomass addition was observed to have significant effects on the thermal profiles of the blends, similar behaviour is expected to happen when bio-oil oil is applied. This hypothesis will be verified further through out this study by varying the proportions of bio-oil added into the coal fuel so that the maximum degradation rates and the best reactivity can be determined by extracting the respective kinetic parameters needed for verification.

\section{Methodology}

Materials and sample preparation: The mixed fuel samples were prepared from Clermont bituminous coal and crude bio-oil as supplied by Kapar Energy Ventures, Selangor and Malaysian Palm Oil Board (MPOB) respectively. Clermont coal (Australia) was commercially used in Malaysia power generation industry. The crude bio-oil was produced from oil palm biomass of empty fruit bunch through thermal conversion process. The mixed fuel which also known as Coalbiooil slurry (CBS) fuel was prepared by firstly air-dried the coal samples for 1-2 days before being crushed into particle size of $0.5 \mathrm{~mm}$ using a cutting mill. Then, the ground coal samples undergone sieving process at particle size of $75 \mu \mathrm{m}$ using digital sieve shaker and later being dried again in an oven at $90{ }^{\circ} \mathrm{C}-100{ }^{\circ} \mathrm{C}$ for 24 hours. Lastly, the coal samples and the crude bio-oil were blended at ratios of $100: 0 ; 90: 10 ; 80: 20 ; 70: 30 ; 60: 40 ; 50: 50$; and $0: 100$ until homogeneous mixture were obtained. The prepared CBS were further analysed using a thermogravimetric analyzer to perform kinetic studies. Several analyses were conducted using Bomb calorimeter for calorific value determination along with ultimate and proximate analysis to review on the fuel characteristics of the mixed fuel and its individual fuel. The details were shown in Table 1 and Table 2.

Thermogravimetric Analyzer (TGA): Thermal analysis on the CBS fuel samples at different ratios was conducted using a TGA (model TG/DTA 6300) under non-isothermal programmed. The samples were loaded at approximately $15 \mathrm{mg}$ and heated from room temperature to $110^{\circ} \mathrm{C}$ and held for 10 minutes before the temperature was ramped to $1100^{\circ} \mathrm{C}$ and was held again for 10 minutes at this temperature. Constant heating rate at $10^{\circ} \mathrm{C} / \mathrm{min}$ was applied under combustive atmosphere of air flowed at $50 \mathrm{~mL} / \mathrm{min}$. Changes in the mass of samples (TG curves) and derivative weight (DTG profiles) were obtained as a function of time and temperature. Kinetic parameters can be extracted from the TG data to accommodate a simple Arrhenius equation for details kinetics studies.

Kinetics Modelling: TGA is capable of providing necessary data for extracting kinetic parameters such as activation energy $(E a)$ and pre-exponential factor $(A)$. It has been widely developed by many correlations depending on its Isothermal or Non-isothermal decomposition kinetics. In this study, non-isothermal analysis at constant heating rate is of interest to relate with thermal behaviour of the respective mixed fuel samples.

Table 1. Characterization of Clermont Coal and Crude Bio-oil samples

\begin{tabular}{|c|c|c|c|c|c|c|c|c|c|c|}
\hline \multirow[t]{2}{*}{ Sample } & \multicolumn{5}{|c|}{$\begin{array}{c}\text { Ultimate Analysis (dry basis), \% } \\
\text { by wt. }\end{array}$} & \multicolumn{4}{|c|}{$\begin{array}{c}\text { Proximate Analysis (dry basis), \% } \\
\text { by wt. }\end{array}$} & \multirow{2}{*}{$\begin{array}{c}\text { Calorific } \\
\text { Value } \\
\text { [MJ/kg] }\end{array}$} \\
\hline & $\mathrm{C}$ & $\mathrm{H}$ & $\mathrm{N}$ & $\mathrm{S}$ & $\mathrm{O}$ & $\begin{array}{l}\text { Volatile } \\
\text { Matter }\end{array}$ & $\begin{array}{l}\text { Fixed } \\
\text { Carbon }\end{array}$ & Ash & Moisture & \\
\hline Bio-oil & 43.22 & 1.34 & 0.71 & 0.14 & $54.59^{\mathrm{a}}$ & 50.79 & 13.25 & 7.79 & 28.17 & 17.9 \\
\hline Coal & 83.3 & 4.59 & 2.02 & 1.02 & $9.07^{\mathrm{a}}$ & 27.7 & $50.4^{\mathrm{a}}$ & 9.0 & 12.9 & 26.9 \\
\hline
\end{tabular}

${ }^{\mathrm{a}}$ Calculated by difference; 
Table 2. Heating values of mixed fuel (Coal-biooil slurry fuel blends)

$\begin{array}{lccccc}\text { Sample Ratios } & 90: 10 & 80: 20 & 70: 30 & 60: 40 & 50: 50 \\ \text { CV (MJ/kg) } & 19.0 & 19.8 & 20.6 & 21.7 & 22.8\end{array}$

The activation energy was obtained from the slope by plotting the plot of $\ln (1 /(1-\alpha)$. $d \alpha / d T)$ vs. $1 / T$ while pre-exponential factor was determined by calculations from the intercept. The reaction rate (rate of conversion) is often expressed by the sample mass loss as a function of temperature as follows [8]:

$$
\frac{d \alpha}{d t}=k(T) f(\alpha)
$$

Where $k$ is the rate constant; $t$ is the reaction time; $\alpha$ is the conversion $\alpha=\left(w_{o}-w\right) /\left(w_{o}-w_{c}\right)$; $w_{o}$ is the initial mass of the sample; $w$ is the mass of sample at time $t$ and $w_{c}$ is the final mass; $\mathrm{T}$ is the absolute temperature, $k(T)$ is the temperature-dependant rate constant and $f(\alpha)$ is the temperature-independent function of conversion. By following the direct Arrhenius's equation $k(T)$ is defined as :

$$
k(T)=A \exp \left(-\frac{E}{R T}\right) .
$$

By assuming a first-order reaction (nth $=1), A\left(\mathrm{~min}^{-1)}, \mathrm{E}(\mathrm{J} / \mathrm{mol}), R(\mathrm{~J} / \mathrm{mol} / \mathrm{K})\right.$, and $T(\mathrm{~K})$ are preexponential factor, apparent activation energy, the universal gas constant (8.314), and the temperature, respectively. With $f(\alpha)=(1-\alpha)^{n}$ combination of Eq.(1) and (2) is expressed as decomposition kinetic equation of :

$$
\frac{d \alpha}{d t}=A \exp \left(-\frac{E}{R T}\right)(1-\alpha)^{n}
$$

Considering non-isothermal constant heating rate $\beta=d T / d t$. Based on direct Arrhenius plot method, the logarithm form for both sides is described as a pattern of linear regression in Eq. (4) as follows:

$$
\ln \left(\frac{1}{1-\alpha} \cdot \frac{d \alpha}{d T}\right)=\ln \left(\frac{A}{\beta}\right)-\frac{E}{R T}
$$

\section{Results and discussion}

\section{Kinetic Analysis on Combustion of Coal-Biooil Slurry (CBS) Blends}

Figure 1 shows the TG profiles of weight loss curves versus temperature of CBS slurry blends at their respective ratios. Even though bio-oil is more reactive than Clermont coal as it is easily ignited due to its volatile matter content, its lower values of energy content is overcome by adding into coal to enhance its combustibility. The information on kinetic parameters was determined by differential method using Arrhenius expression to evaluate the combustion performance where main weight loss occurs at the stage of oxidation. The details are shown in Table 3 together with the aids of direct plot of Arrhenius shown in Figure 2. With linearity above $90 \%$ obtained for every single fuels 
and mixtures, it shows that the validity of the assumptions on first-order decomposition mechanism is fitted with the experimental data [9]. Table 3 showed that the values of activation energy, $E \alpha$ and pre-exponential factor, $A$ increased with the addition of bio-oil into the slurry blends.

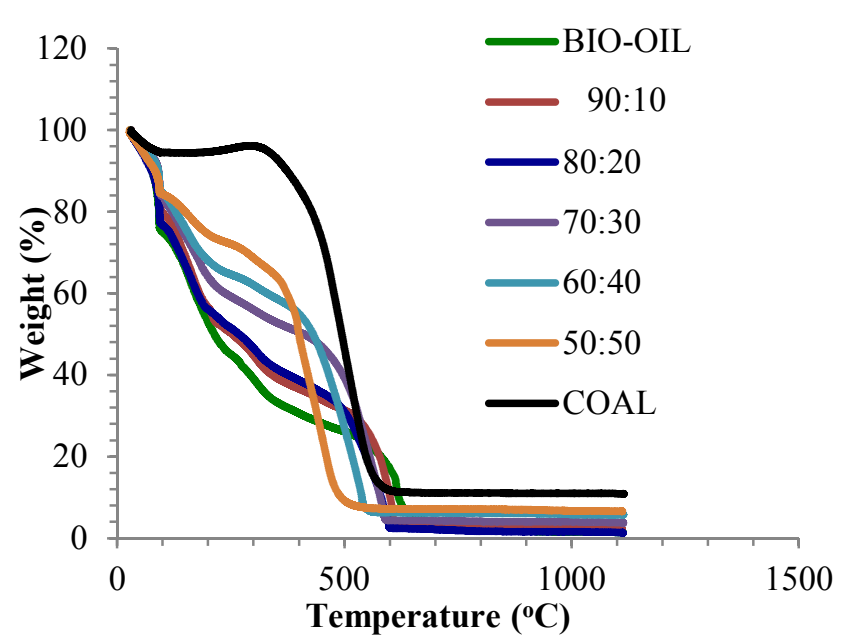

Fig. 1 TG curves for Clermont coal, Bio-oil and their respective blends at constant heating rate of $10{ }^{\circ} \mathrm{C} / \mathrm{min}$ under air atmosphere.

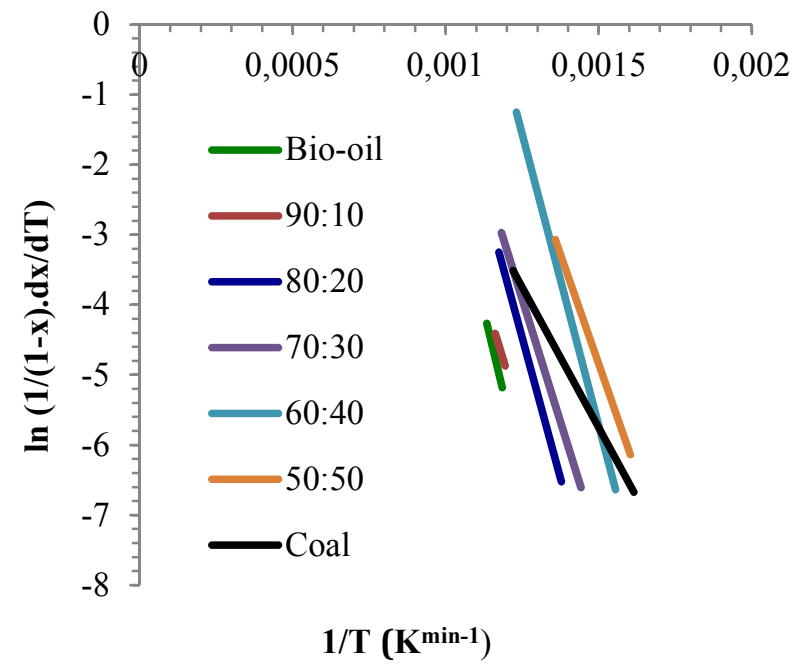

Fig.2 Direct Arrhenius plots method for constant heating rate of $10{ }^{\circ} \mathrm{C} / \mathrm{min}$ under air atmosphere.

As bio-oil is added into coal mixtures, the reactivity will increase thus promoting lesser time for thermal decomposition to occur and the combustion temperature (ignition) was observed to have shifted into lower temperature region. In this case, the mixed fuel with lower activation energy is mostly preferable. Despite of the lower activation preferences, the heating value of the mixed fuel is recommended to be more than $20 \mathrm{MJ} / \mathrm{kg}$ for auto-thermal combustion to occur [10]. This recommendation has been previously applied to biomass/coal fuel blends to compensate for the lower heating values of the biomass source compared to coal for energy content recovery.

Based on Table 3, it is obvious that the optimum blends were chosen among 70:30 to 50:50 ratio blends, as it possessed lower activation energy. However, with regards to the heating value preferences to match with the ideal fuel properties, 50:50 of coal/biooil blends is being selected to be the optimum slurry fuel, as it possessed the highest heating value of $22.8 \mathrm{MJ} / \mathrm{kg}$. Besides, 50:50 blends also needed a much shorter time to decompose compared to other blends, which able to achieve thermal stability at much lower temperature region at around $500{ }^{\circ} \mathrm{C}$ and easily ignited. Not only that, $50: 50$ blends also results in maximum rate of weight loss of about $70-60 \mathrm{wt} . \%$ of the fuel is combusted (volatile matter decomposition contributed by bio-oil addition) at $400{ }^{\circ} \mathrm{C}$. A reactive blend is observed to have yield maximum combustion rate at lower temperatures.

Table 3. Kinetic parameters of Coal-biooil slurry fuel blends

\begin{tabular}{ccccc}
\hline Fuel & Blend ratio & $\mathbf{E}_{\boldsymbol{\alpha}}(\mathbf{k J} / \mathbf{m o l})$ & $\mathbf{A}\left(\mathbf{m i n}^{-1}\right)$ & $\mathbf{R}^{2}$ \\
\hline Bio-oil & $100: 0$ & 145.74 & $5.80 \times 10^{7}$ & 0.9624 \\
B: C & $90: 10$ & 120.54 & $2.43 \times 10^{6}$ & 0.9000 \\
B: C & $80: 20$ & 119.70 & $6.40 \times 10^{6}$ & 0.9902 \\
B: C & $70: 30$ & 111.48 & $2.63 \times 10^{6}$ & 0.9764 \\
B: C & $60: 40$ & 110.14 & $7.42 \times 10^{6}$ & 0.9274 \\
B: C & $50: 50$ & 88.35 & $6.76 \times 10^{5}$ & 0.9349 \\
Coal & $0: 100$ & 78.82 & $3.71 \times 10^{4}$ & 0.9731 \\
\hline
\end{tabular}




\section{Conclusion}

The kinetics parameters increased with increasing percentage of bio-oil in the blends. Therefore lowest activation energy is preferable with 50:50 blends appears to be the optimum fuel with high degradation rate at about $60 \mathrm{wt} . \%$. The addition of crude bio-oil to Clermont coal has the same influence on the pre-exponential factor, $A$, which it reflects the reactivity of the different types of fuel. The addition of bio-oil to coal could increased the reactivity of the Clermont coal when acted as single fuel thus promoting lesser time for decomposition to occur where the temperature region is observed to have shifted into lower temperature regions.

\section{Acknowledgement}

The authors gratefully acknowledge the financial support from Ministry of Education Malaysia via the Research Acculturation Grant Scheme (RAGS/2012/UITM/TK07/1).

\section{References}

[1] A. Demirbaş, Sustainable cofiring of biomass with coal, J.Energy Conver and Man. 44 (2003) 1465-1479.

[2] B. D. Bals and B. E. Dale, Developing a model for assessing biomass processing technologies within a local biomass processing depot, J. Bioresour Technol. 106 (2012) 161-169.

[3] N. Abdullah and H. Gerhauser, Bio-oil derived from empty fruit bunches,J. Fuel. 87 (2008) 2606-2613.

[4] L. Li, X. Yin, C. Wu, L. Ma, and Z. Zhaoqiu, Kinetic Studies on the Pyrolysis and Combustion of Bio-oil, in ISES Solar World Congress 2007: Solar Energy and Human Settlement, 2007.

[5] H. Hamdan, M. Z. Shahruddin, A. R. M. Daud, and S. S. A. Syed-Hassan, Thermal Behaviour of Slurry Prepared from Clermont Bituminous Coal and Oil Palm Empty Fruit Bunch Bio-oil, Adv. Materials Research. 906 (2014) 153-158.

[6] P. Pimenidou and V. Dupont, Characterisation of palm empty fruit bunch (PEFB) and pinewood bio-oils and kinetics of their thermal degradation, J.Bioresour Technol. 109 (2012) 198-205.

[7] A. Tahmasebi, M. A. Kassim, J. Yu, and S. Bhattacharya, Thermogravimetric study of the combustion of Tetraselmis suecica microalgae and its blend with a Victorian brown coal in $\mathrm{O}_{2} / \mathrm{N}_{2}$ and $\mathrm{O}_{2} / \mathrm{CO}_{2}$ atmopheres, J.Bioresour Technol. 150 (2013) 15-27.

[8] M. V. Gil, D. Casal, C. Pevida, J. J. Pis, and F. Rubiera, Thermal behaviour and kinetics of coal/biomass blends during co-combustion,J. Bioresour Technol. 101 (2010) 5601-5608.

[9] E. Biagini, F. Lippi, L. Petarca, and L. Tognotti, Devolatilization rate of biomasses and coal-biomass blends: an experimental investigation,J. Fuel. 81 (2002) 1041-1050. 